\title{
Application and Selection of Green Materials in Building Interior Space
}

\author{
Xikuan Zhang ${ }^{1}$ \\ 1 University of Science and Technology Liaoning, Anshan Liaoning 114051, \\ China sunenyu@126.com
}

Keywords: Green Materials,interior Space,Protect the environment

ABSTRACT: The significance of green materials to the building interior space is not only to bring about the improvement of human living space, but also to protect the environment. It is also a high level of experience which brings people spirit and culture.

\section{Introduction}

From the angle of reducing the material to the environment, the effective way to solve the problem of material selection in the traditional design is to develop the green material, which is not a kind of new material, but mainly from the point of view of its contribution to the environment or environmental protection.

Or eco materials, which have good use performance or function, and less consumption of resources and energy, environmental pollution is small, is conducive to human health, renewable utilization, recycling, use, waste recycling and environmental protection in the whole process, the integration of environmental protection and environmental protection is a major type of material.

\section{Selection of green materials}

Green materials research and application of the main premise is the evaluation and selection of green materials, domestic and foreign scholars have done a lot of research in this area, and put forward a number of evaluation and selection method, selection of green materials should pay attention to the following points:

Non toxic and harmless, including chemical stability and biological safety, to avoid the greenhouse effect and ozone layer damage, etc.;

The whole life cycle energy consumption and resource consumption are very low;

Can be recycled, recyclable, easy to recycle;

The structure is stable and reliable, the utilization rate is high;

Reduce environmental pollution, protect the environment and so on.Green indoor environment mainly refers to non pollution, pollution-free, sustainable, help to the health of consumers of the indoor environment. In the design, as far as possible the selection of energysaving type material, give full consideration to the interior space of the loading capacity and ventilation; in the process, as far as possible to reduce construction dust, noise, exhaust, waste water to the environment pollution and destruction, and the importance of the disposal of waste; in the decoration materials and strict selection of formaldehyde free glue, big core board, veneer, benzene in the paint, gypsum board, and try to choose high utilization rate, the use of renewable, low resource consumption of composite material.

\section{Application method of green material}

Harmony with spatial layout.Green design is a new design idea, which emphasizes the protection of natural ecology, full use of resources, people-oriented, friendly environment. Green design pays attention to the harmonious development of human and nature. It can meet the 
requirements of ventilation and natural lighting, and can satisfy the requirement of ventilation and natural lighting. It is necessary to establish the design basis, and to find out the environment structure.

Response to functional form. Indoor noise source.Currently indoor noise pollution mainly in low frequency sound wave and vibration, has low loudness, strong penetrating power, long lasting characteristics mainly are from the following: through the doors and windows in the outdoor noise; through household wall into the neighbors living voice; the indoor heating, drainage pipeline transmission of sound; by building on the ground floor and conduction of sound; through the pumping station building, elevator equipment conduction sound. Noise hazard.For residential bedroom, the living room of the allowable noise level, national standards should be less than or equal to $50 \mathrm{~dB}$, the night should be less than or equal to $40 \mathrm{~dB}$. People's sleep and rest will be disturbed when the indoor noise exceeds $30 \mathrm{~dB}$.In particular, the sound insulation is not good room, will make people have mental disorders, memory loss, anxiety and other symptoms, affect people's normal life and health. Noise processing.Ecological Interior Design for different noise sources, take different measures to eliminate, isolation of noise. First, reasonable arrangements for housing patterns, so that there is room for quiet as far away from the sound source; followed by the selection of suitable structure and sound insulation material, such as hollow double glass windows and plastic steel flat open window seal, can also through the correct fitting to make up for the deficiency of the layout of the room, on the indoor pipeline use insulation materials packaging to reduce sound transmission pipeline.

Indoor light environment.Indoor light pollution.Continuously improve the level of household and three light pollution, the visual environment pollution, according to their location can be roughly divided into indoor and outdoor, local inspect environmental pollution, according to its mode can be divided into white light pollution, artificial daylight color light pollution. As people, indoor light pollution can not be ignored. Room light pollution causes can be summarized as three aspects: interior decoration with mirror, glazed brick walls, polished marble and a variety of paint and other decorative light reflection, glare; indoor lighting configuration design unreasonable, resulting in indoor light is too bright or too dark; the night outside the room lighting, especially building floodlight illumination light interference, affecting people's normal life.Light pollution hazard.Glare can affect visibility, reducing light efficiency, heavy complete loss of vision, bring very great harm to people's life and work. Health experts think, the main reason for the formation of myopia is visual environment, rather than using eye habits, for family health should be a reasonable selection of lamps and light sources.Light pollution treatment.China should formulate pollution control standards and norms as soon as possible; the provisions of our existing legal system of light pollution is still a blank state, according to the actual situation of China, you can modify the $\langle>>$ the civil law environmental protection law and relevant laws, improve relevant laws and regulations of environmental protection dispute resolution procedures, increase accountability caused by light pollution. The administrative, civil, criminal liability regulation. Selection and layout of the indoor light source need standardization; under the premise of ensuring proper indoor illumination, to avoid the use of decorative materials of high reflection coefficient; the establishment of indoor light environment energy optimization control system, coordination of natural lighting and artificial lighting, with adjustable lighting. Such as the shallow water of Hongkong bay bus station commercial lighting design minimalist style material, create a comfortable and natural scene, in order to increase the visual sense of space. In a plain background, whether strong contrast, or harmonious taste, can highlight every interior design, so that the original simple space to become vivid.

Indoor air pollution.Indoor air pollution sources. indoor decoration materials harmful substances limited 10 mandatory national standards $>$ the harmful substances pollution sources do the detailed description, which the most important is: man-made board and its products, solvent coatings for woodenware, interior wall paint, solvent based adhesives, wooden furniture, wallpaper, carpet and carpet adhesive. Indoor air pollution is main reason affecting indoor air quality, and 
related pollution from people's daily activities, such as gas cooker, home appliances, smoking, cosmetic, health care, etc. and the body's own breathing, metabolism also generate pollution.Indoor air pollution hazard.Indoor air pollution is mainly chemical pollutants, such as formaldehyde, long-term exposure can cause nasal, oral, throat, skin and digestive tract cancer, and other formaldehyde and the role of a baby.Indoor air pollution treatment.Designers should take the protection of the environment and the rational layout of indoor space, and careful selection of green materials, can be used to control pollution from the source. Due to the pollution caused by human activities is inevitable, but take measures such as strengthening indoor ventilation, reasonable layout of green plants, etc. can also be harmful to the health of the pollution control range.Combined with structural technology.An important factor in the interior decoration of the construction technology is also affecting the ecological environment. People used to traditional field production construction practices, not only waste a lot of manpower, material, but also caused serious dust, air pollution, this pollution usually do not have adapted protection and recovery measures, so from the point of view of technology structure design should as far as possible the use of semi-finished processing factory, finished, using assembly type structure, to reduce the field of production.

\section{Introduction of natural elements}

To create a pleasant ecological environment by introducing or reproduction of the natural landscape to indoor space with vitality, to better meet the human physiological and psychological needs. Usually, the designer can use: the introduction of natural landscape, space inside and outside circulation, using bionic principle, application of local materials and methods for green design in interior design man is an organic part of the natural ecological system, natural elements and people have an inherent sense of harmony. People not only have personal, family, social attributes and social activities, is more close to the sun, air, water, natural green plants and other natural elements. Therefore, the natural elements in interior design reference a logical thing.

\section{Conclusion}

The green design of building interior space will become the inevitable trend of the development of interior design, and the green material is the concrete embodiment of interior green design, creating a comfortable, safe, practical, economical and beautiful indoor green environment.

\section{References}

[1] Caiping Liu. On green building design, Chinese high tech Enterprises (24).2013.

[2] Jinye Liu. Methods for building energy efficiency design, Technology to get rich guide (18).2014.

[3] Wei Wang. Preliminary study on green building design, Building materials and decoration (05).2011.

[4] Xiangyang Wu. Two ways of green building design, Journal of architecture (7).2010. 